\title{
EXAMPLES OF ANTHROPOGENIC SINKHOLES IN SICILY AND COMPARISON WITH SIMILAR PHENOMENA IN SOUTHERN ITALY
}

\author{
Marco Vattano, Cipriano Di Maggio, Givliana Madonia \\ Dipartimento di Scienze della Terra e del Mare, University of Palermo, Via Archirafi 22, Palermo 90123, Italy, \\ marco.vattano@unipa.it
}

Mario Parise, Piernicola Lollino

CNR IRPI,Via Amendola, 122/I, Bari 70126,Italy,m.parise@ba.irpi.cnr.it

\section{Marco Bonamini}

Via Trinacria 8, Palermo 90144, Italy, bonamini@neomedia.it

\begin{abstract}
Anthropogenic sinkholes affect several built-up areas of Sicily (southern Italy) representing a great risk to people, buildings, and infrastructures. These phenomena are generally associated with the presence of ancient underground quarries for the extraction of calcarenite rock, used for building or ornamental materials. These quarries were poorly constructed and abandoned throughout history.

Field surveys, structural analysis of the fissure networks in the rock mass, and numerical modeling were carried out in order to understand the most significant factors responsible of the instability processes of underground quarries. The genetic mechanisms of anthropogenic sinkholes have also been investigated. Jointing and saturation conditions of the calcarenite, along with indiscriminate enlargement of voids, can reduce the available strength. This strength is needed to maintain the stability of the rock mass above the underground quarry, the lack of which can cause the sinkholes formation.
\end{abstract}

Finally, a comparison between the cases of Sicily and Apulia regions, where similar anthropogenic sinkholes are widespread, was carried.

\section{Introduction}

Anthropogenic sinkholes and subsidence phenomena are very widespread and generally linked to the presence of man-made caves, such as quarries and mines, or due to indiscriminate extraction of fluids including water, oil, and gas (Waltham, 2002; Waltham et al., 2005).
Many built-up areas of Sicily (southern Italy) are affected by such type of risk. In particular, Marsala (western end of Sicily, Figure 1) was affected in the past decades by several collapse phenomena which caused extensive damage to infrastructures and population. These phenomena are related to the presence of underground quarries for the extraction of calcarenites used as building materials.

These cavities are carved at depth varying from several meters to roughly $25 \mathrm{~m}$ on a single or superimposed layer, following the excavation techniques of chambers and passages separated by rock pillars. However, excavation typically occurred without any planning.

With time, the underground quarries were progressively abandoned for several reasons (i.e., interaction with the percolating waters, decay of the physical-mechanical properties of the rock, high costs, difficulties and risk excavation work).

Nowadays in many cavities signs of instability can be clearly recognized along ceilings, walls and pillars. These instabilities easily propagate upwards causing sinkhole and subsidence phenomena according to the mechanisms described in Parise \& Lollino (2011), thus creating consistent damages to buildings and infrastructures.

A sinkhole, occurred in June 2011 and related to an underground quarry in the eastern sector of Marsala, is described in this paper as a case study (Figure 2). The site was selected for the availability of topographic data of the underground quarry, prior to the formation of the 


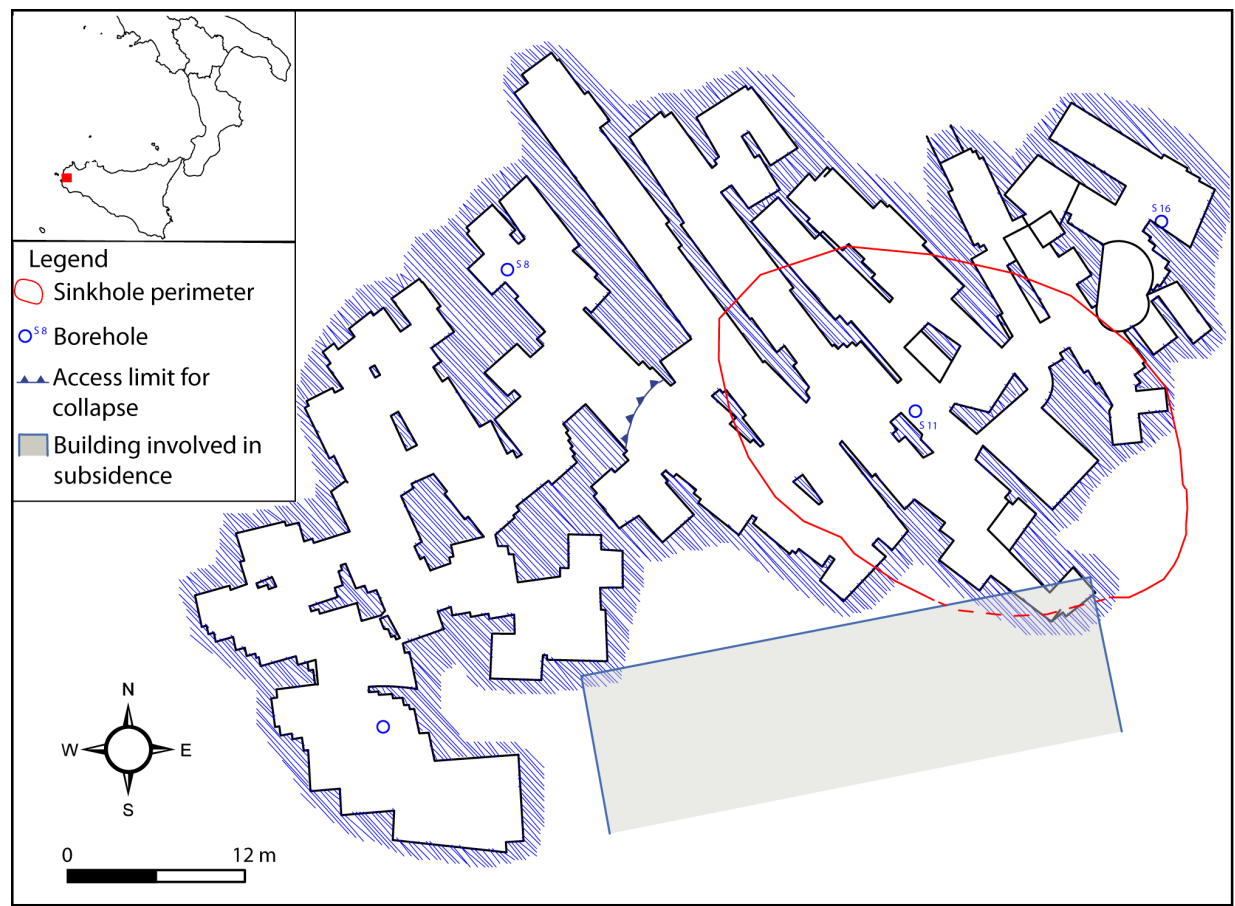

Figure 1. Planimetric view of the studied underground quarry. In the inset, location of the Marsala area.

sinkhole, which were useful for defining the genetic mechanisms of this depression. The quarry was surveyed in 2000. During this survey various signs of instability, such as open fractures and detachment of large blocks, were observed on the vaults and at the pillars. After the June 2011 sinkhole, new surveys were conducted inside the quarry aimed at collecting additional data to better understand the factors that have played a role in generating the sinkhole (Figure 2).

Since the collapse occluded many of the remaining rooms, the 2011 surveys were limited to the western sector of the quarry (Figures 1 and 3A). Detailed surface topographic surveys were conducted in the following months to detect new signs of collapse or movements of the topographic surface.

In this article, we intend to describe the geological and structural features of the site study, and illustrate the preliminary results about the genesis of sinkholes obtained using finite element analyses. The numerical modeling was implemented following a similar procedure applied in other site studies in southern Italy (Parise \& Lollino, 2011; Parise, 2012; Lollino et al., 2013). Finally, a comparison between the cases of Sicily and similar anthropogenic sinkholes of Apulia region was made, in order to gain a better understanding of the mechanisms causing the sinkholes.

\section{Geological setting}

In the Marsala area Lower Pleistocene calcarenites, defined as "Calcarenite di Marsala" (Ruggieri \& Unti, 1974; Ruggieri et al., 1975) and referred to the Marsala syntheme, crop out (Di Maggio et al., 2009). They are formed by three main lithofacies with vertical and lateral passages: a) coarse to fine yellow bio- and lithoclastic calcarenites, rich in macrofossils; b) sands; and c) gray sandy clays. Both b and c types are rich in microfossils. The calcarenites and the sands show a gradual lateral transition to sandy clays and silts which generally can be found at the base of the entire sequence.

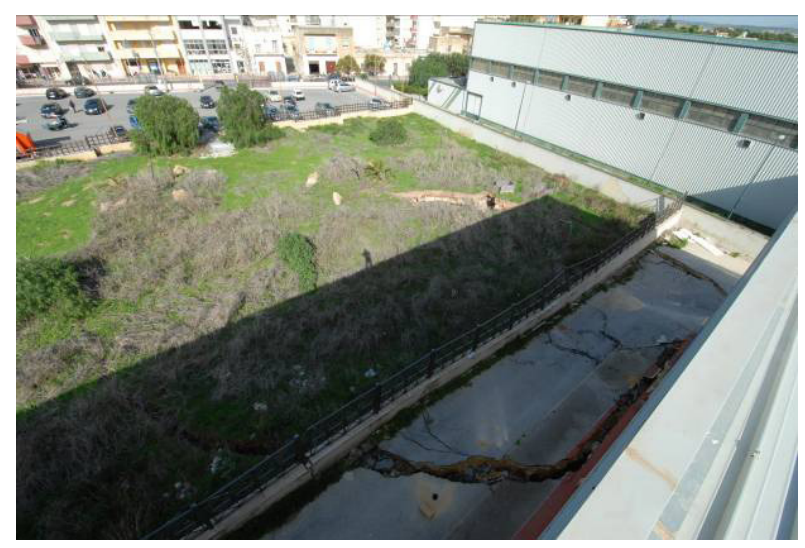

Figure 2. The sinkhole formed in June 2011 , in correspondence of the quarry in Figure 1. 
According to Ruggieri et al. (1975) and Arces et al. (2000), the calcarenitic lithofacies can be divided into three lithotypes: i) coarse calcarenites and calcirudites strata, from 10 to $100 \mathrm{~cm}$ thick; ii) fine to coarse calcarenites with thickened grains; iii) medium to coarse calcarenites in irregular strata with intercalations of thin beds of silt. Usually the ii) type was carved in the quarries. The overall succession, at least $80 \mathrm{~m}$-thick, gently dips $\left(5-10^{\circ}\right)$ towards the south and the southwest. The calcarenites are affected by intense high-angle fracture systems showing NW-SE and, subordinately, E-W direction (Figure 4A). In some locations, the Marsala Calcarenite is covered by Middle and Upper Pleistocene marine terraced deposits. In the underground quarry, chosen as a study case, the mining activity involved exclusively the fine to coarse calcarenites.

\section{The sinkhole and the underground quarry}

In June 2011 a sinkhole occurred in correspondence of an underground quarry, damaging several constructions, including a recreation centre and the

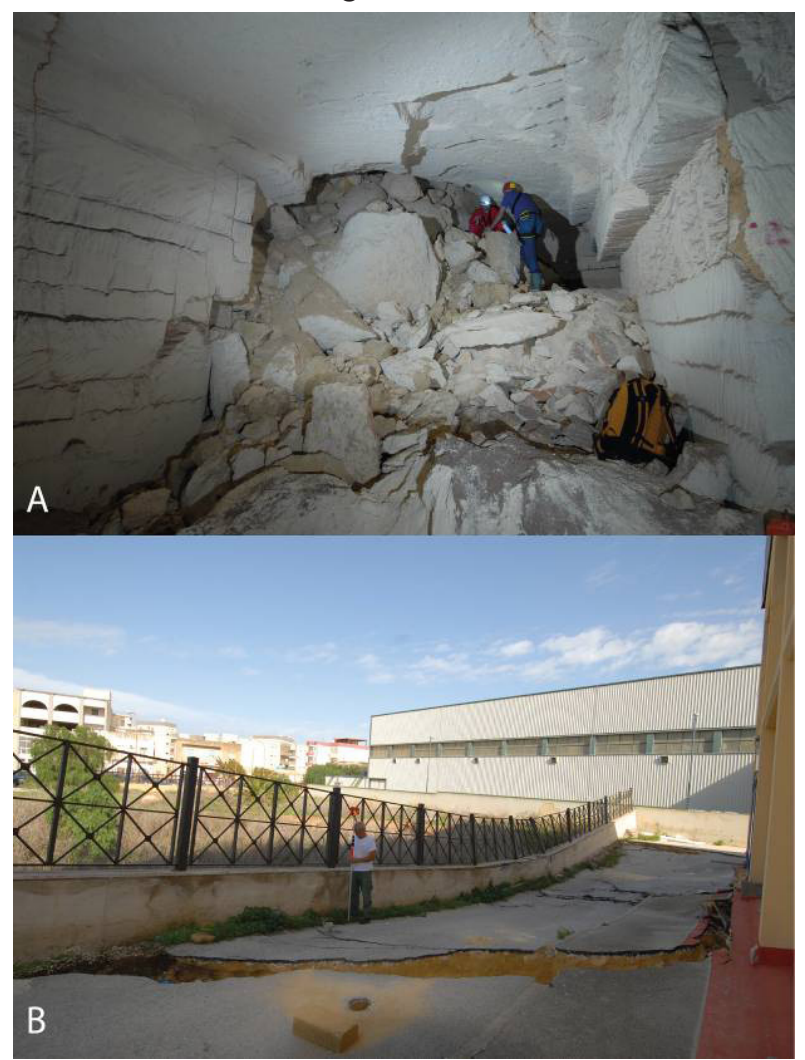

Figure 3. Sinkhole formed in June 2011. A: Breakdown deposits within the quarry in the proximity of the area affected by the sinkhole. B: Damage caused by the sinkhole to the overlying buildings. nearby infrastructures (Figures 2 and 3B). A detailed topographic survey was conducted in order to define the perimeter, shape and depth of the sinkhole.

The survey was carried out using a topographic station, measuring at points with a grid spacing of $2.5 \mathrm{~m}$, because of the presence of thick vegetation and the pronounced topography (Figure 7).

The sinkhole has an elliptical shape with a maximum diameter of $130 \mathrm{~m}$, a minimum of $90 \mathrm{~m}$ and a maximum depth of $2.4 \mathrm{~m}$. It is asymmetric with the deepest point located in the eastern sector, characterized by a $2 \mathrm{~m}$-high scarp and a direction of elongation (NW-SE) parallel to both the underground galleries and the main tectonic discontinuities of the area.

During the months following the formation of the sinkhole a total of 4 survey campaigns were performed in order to evaluate the likely progressive evolution at

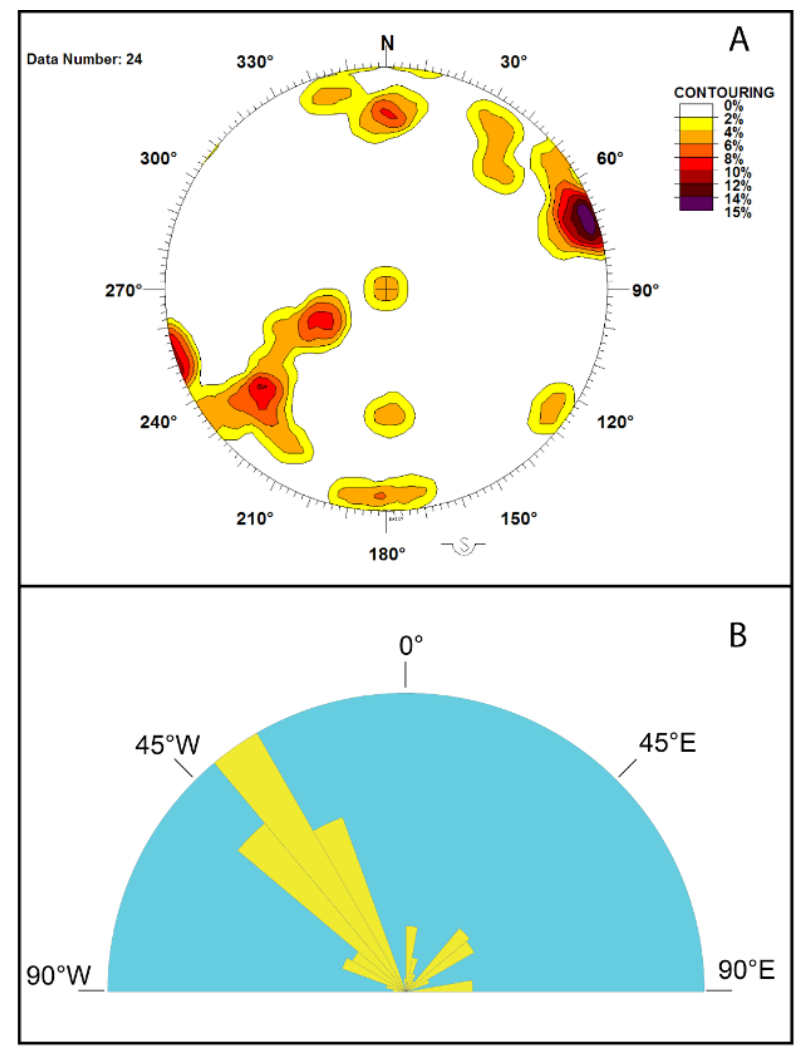

Figure 4. Stereographic projection (Schmidt, lower hemisphere) of the poles of the fracture plans in the calcarenite rock mass, as from the survey within the quarry (data elaboration by means of Daisy 3; Salvini, 201 1). B: Main development directions of the underground passages. 
the site. These measurements, performed along a crosssection $(E-W)$ in the southern flank of the sinkhole, did not show any consistent variation of the topographic level (Figure 3B).

The underlying quarry consists of a series of rooms with quadrangular shape, in most cases connected and/or separated by thin rock walls or pillars. NW-SE oriented galleries, separated by thin rock walls, are present in the central sector of the quarry (Figures 1 and 4B).

The room size is highly variable: the average height is $2.7 \mathrm{~m}$, ranging between 1.1 and $7.5 \mathrm{~m}$.; the average width is roughly $3.5 \mathrm{~m}(1.8-8 \mathrm{~m})$; the average length is $12 \mathrm{~m}$ $(2.6-40 \mathrm{~m})$. The walls are $20 \mathrm{~cm}$ to $4 \mathrm{~m}$ thick, whilst the pillars have a width varying from $30 \mathrm{~cm}$ to $4 \mathrm{~m}$, and a length between $70 \mathrm{~cm}$ and $6 \mathrm{~m}$. Overall, the quarry is 480 $\mathrm{m}$ long, with overburden varying from 8.2 to $11.8 \mathrm{~m}$. The calcarenite was extracted along variable directions. The pattern of the quarry is mainly influenced by the quality of the rock and the perimeter of the land properties. Shape and distributions of the rooms display very different directions in the western sector of the quarry. The central and eastern sector of the quarry, instead, show preferential excavation direction as inferred by the presence of rooms and galleries tens of meters long and with direction (NW-SE) parallel to the main rock discontinuities (Figure 4). The enlargement of the quarry following the principal discontinuity directions was necessary to extract entire blocks of calcarenite.

\section{Instability phenomena inside the quarry}

Inside the quarry, signs of instability at different stages of evolution are visible along the ceilings, the walls and the pillars.

Instabilities are generally due to the fracture system of the calcarenite body, the dense and irregular distribution of rooms and galleries, and the rock alteration caused by water infiltration. Sub-vertical fractures, and fracture parallel or coincident with the bedding planes caused detachment of large volumes of rock from the vaults (Figure 5).

According to the 2000 survey, falls were mainly located in the eastern sector of the quarry where rooms are larger and separated by small rock pillars and walls, only $30 \mathrm{~cm}$ thick. In this sector, movements of large portions of rocks following the sub-vertical fractures were also detected, in addition to falls. This sector is located in the area where the sinkhole occurred. Along these fractures, saturation and chemical alteration due to the percolating water are visible. The walls are affected by a joint system parallel to the walls, with presence of both incipient fractures and tensile joints with aperture of several centimeters.

Two types of fractures can be recognized: fractures preexistent to excavation of the quarry, and fractures caused by the local instability of rocks inside the quarry.

The first type of fractures are continuous along the ceilings of different rooms, and are mainly tensile fractures with visible signs of rock alteration due to the water circulation. In the second type, along the
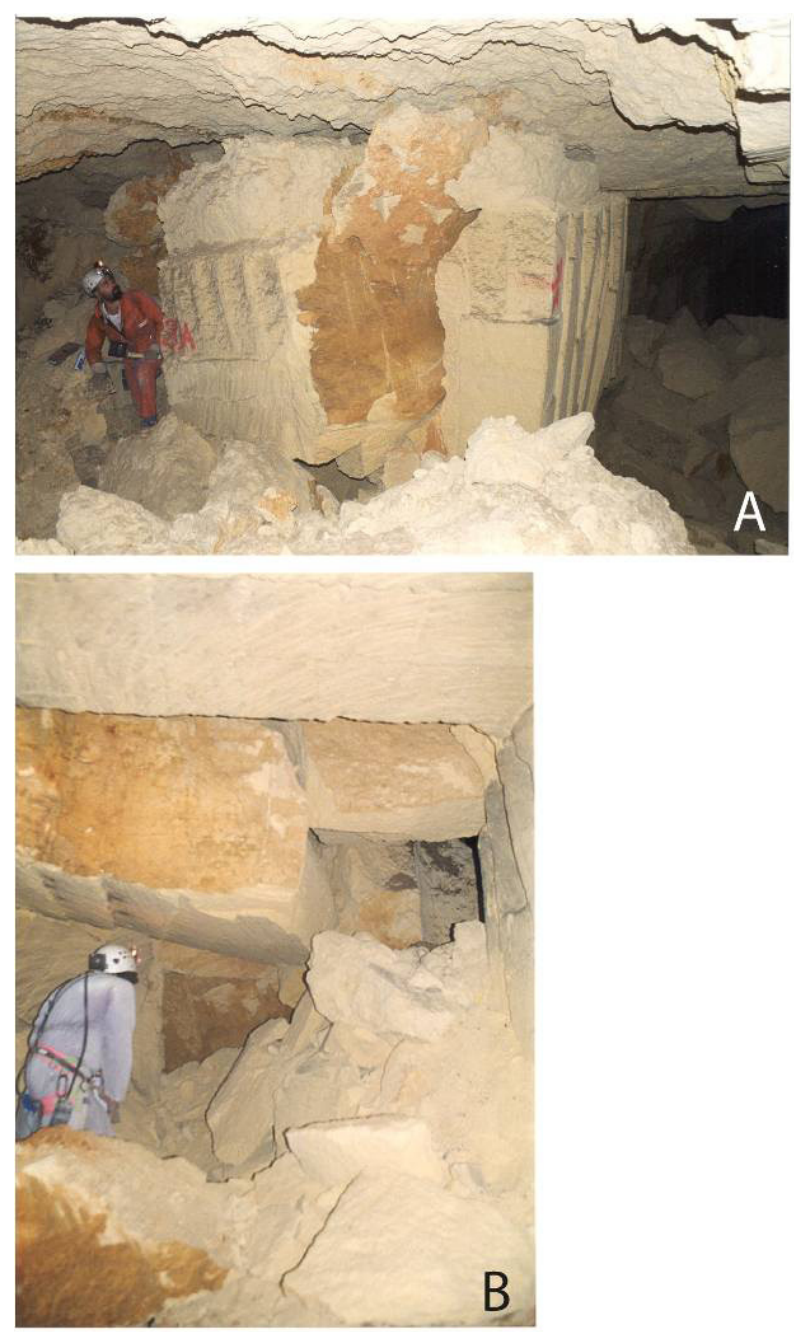

Figure 5. Instability phenomena in the quarry vaults. Falls (photo A) and movements of large volumes of rock along sub-vertical fractures (photo B) surveyed in 2000, in correspondence of the sector where the sinkhole formed. 
discontinuities, the deformations of the calcarenitic rock are visible with outward protrusion of wedges. Both types of fractures can isolate slices of rock of variable thickness which at later stages can cause collapse.

The rock pillars are also characterized by joint systems with different inclinations and aperture ratio. Some of these were pre-existent to the formation of the quarry, while others appear to have been caused by the high level of stress of the calcarenitic rock pushing the pillars.

These fractures can isolate blocks of metric size, causing failures from the corner of the pillars. In some cases, the fractures can run along the entire length of the pillars, causing a reduction in thickness and, eventually collapse (Figure 6).

\section{Finite element analysis}

Adetailed geotechnical characterization of the Pleistocene calcarenite of Marsala is described in Arces et al. (2000). The rock is a medium-fine grained material, which can

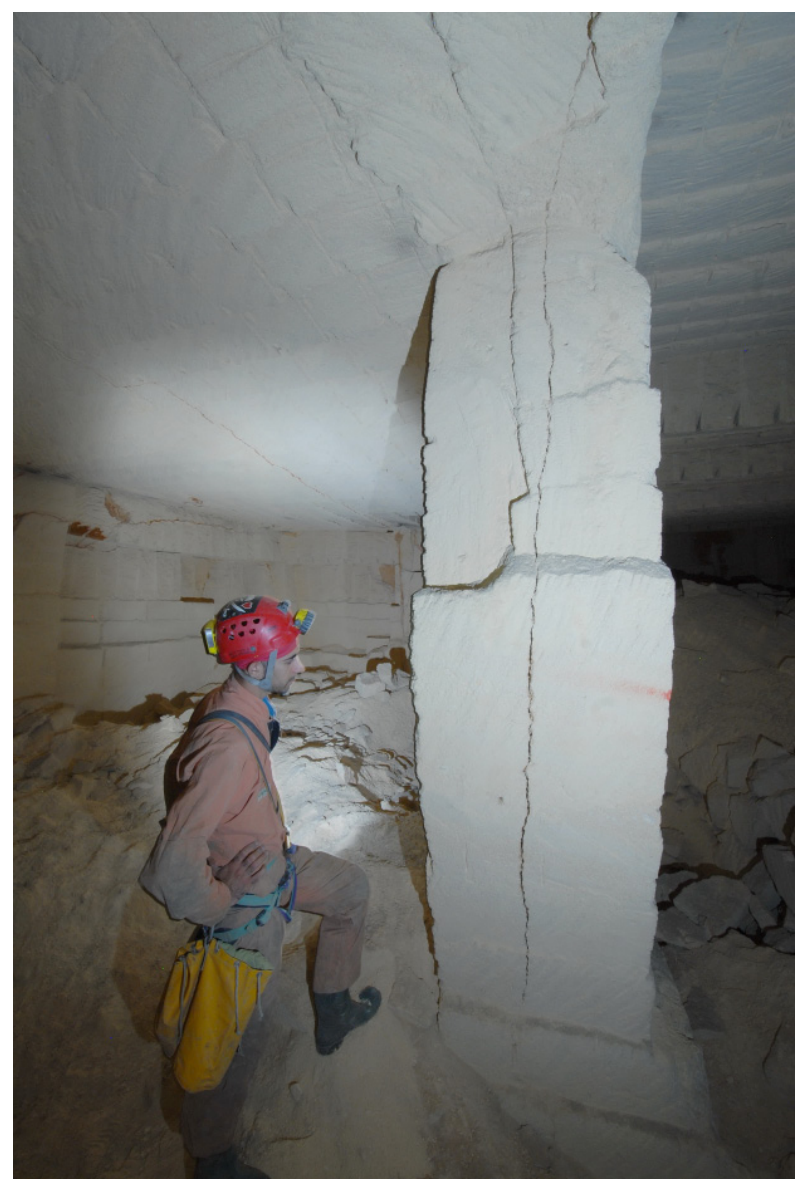

Figure 6. Sub-vertical joint crossing a quarry pillar. be classified as very to extremely soft rock, according to the recommendations provided by the International Society for Rock Mechanics (ISRM). In particular, Arces and co-workers highlight the significant influence of the saturation ratio on the uniaxial compression strength of the calcarenite samples, with strength values under saturated conditions $\left(\sigma_{c}=1.3-1.6 \mathrm{MPa}\right)$ about half of the corresponding values for saturation degree equal to zero $\left(\sigma_{c}=2-3 \mathrm{MPa}\right)$. A similar reduction in the values was also observed for the modulus of elasticity, measured at $50 \%$ of the uniaxial strength $\left(\mathrm{E}^{\prime}{ }_{50}\right)$, with values ranging between $0.03 \times 10^{4}$ and $0.08 \times 10^{4} \mathrm{MPa}$.

In the following model, the value of the tensile strength has been assumed to be $1 / 10$ of the compressive strength, that is equal to $\sigma_{t}=130-160 \mathrm{kPa}$ for saturated rock and $\sigma_{t}=200-300 \mathrm{kPa}$ for dry conditions. Under saturated conditions, the shear strength parameters according to the Mohr-Coulomb failure criterion result to be $c^{\prime}=110$ - $150 \mathrm{kPa}$ and $\varphi^{\prime}=35^{\circ}$. Further, values of $\mathrm{c}^{\prime}=165$ $220 \mathrm{kPa}$ and $\varphi^{\prime}=35^{\circ}$ have also been considered in order to simulate conditions of low saturation degree of the calcarenite rock mass.

These parameters have been obtained as a linear approximation of the shear strength envelopes according to the Hoek-Brown failure criterion, accounting for a stress level representative of the in-situ conditions and a GSI value (Geological Strength Index; Hoek, 1994) equal to 95 .

The specific parameters adopted in the model are listed in Table 1.

Table 1. Parameters adapted in the FEM analysis.

\begin{tabular}{|c|c|l|c|}
\hline & $\begin{array}{l}\text { Dry Calcarenite } \\
\text { GSI }=95\end{array}$ & $\begin{array}{l}\text { Saturated } \\
\text { Calcarenite } \\
=1) \\
\text { GSI }=95\end{array}$ & $\begin{array}{l}\text { Saturated } \\
\text { Calcar- } \\
\text { enite } \\
(\mathrm{S}=1) \\
\text { GSI }=80\end{array}$ \\
\hline $\mathrm{g}\left(\mathrm{kN} / \mathrm{m}^{3}\right)$ & 15 & 15 & 15 \\
\hline $\begin{array}{c}\mathrm{E}^{\prime} \\
(\mathrm{MPa})\end{array}$ & 600 & 300 & 300 \\
\hline $\mathrm{n}^{\prime}$ & 0.3 & 0.3 & 0.3 \\
\hline $\mathrm{c}^{\prime}(\mathrm{kPa})$ & 165 & 110 & 75 \\
\hline $\mathrm{j}^{\prime}\left({ }^{\circ}\right)$ & 35 & 35 & 35 \\
\hline$\sigma_{\mathrm{t}}(\mathrm{kPa})$ & 200 & 130 & 130 \\
\hline$\sigma_{\mathrm{c}}(\mathrm{kPa})$ & 2000 & 1300 & 1300 \\
\hline
\end{tabular}




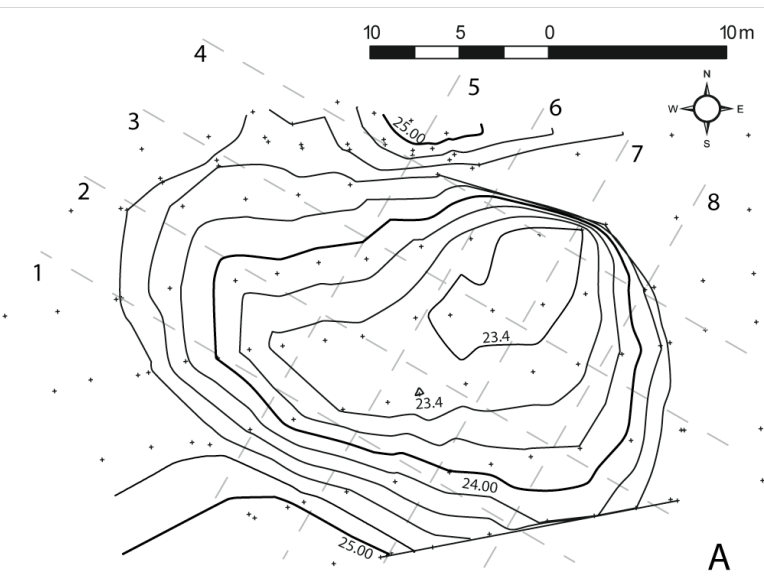

A
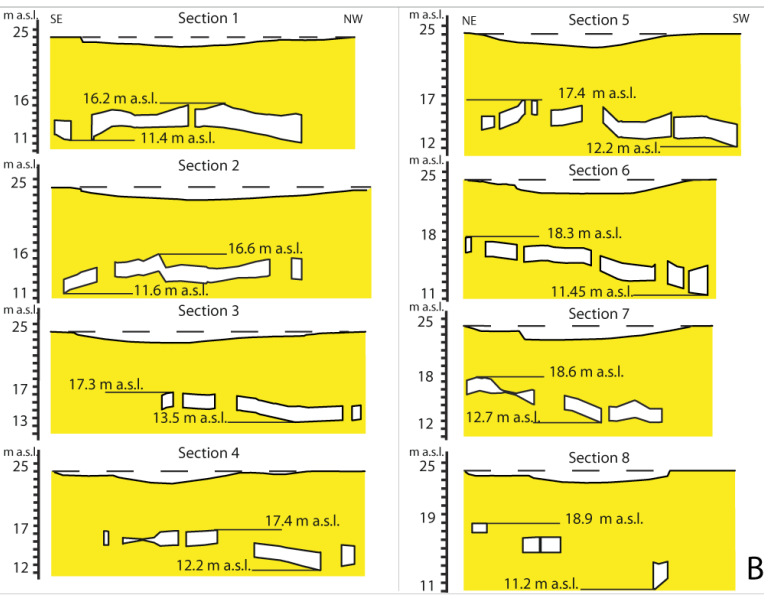

Figure 7. A: Detailed topographic survey of the June 2011 sinkhole. Dashed lines indicate traces of the cross sections shown in figure $7 B$; crosses mark the topographic measurement stations. B: Cross sections of the sinkhole and the corresponding underground quarry sectors. Dashed line indicates the topography before the occurrence of the sinkhole.

Aimed at the reconstruction of the conditions that formed the sinkhole in the eastern sector of Marsala, a back-analysis with the finite element method (FEM) has been performed. Indeed, this method allows to simulate the elasto-plastic stress-strain evolution of continuous rock masses affected by the presence of underground cavities (Parise \& Lollino, 2011). A two-dimensional analysis has been implemented with the numerical code PLAXIS $^{2 D}$ (Plaxis-BV 2010) by considering the cross section 6 shown in Figure 7. The constitutive model chosen for the rock mass is elastic-perfectly plastic with Mohr-Coulomb failure criterion, non associated flow $(\psi$ $=0^{\circ}$ ) and tension cut-off.

The analyses have been carried out in drained conditions and assuming the whole domain above the water table,

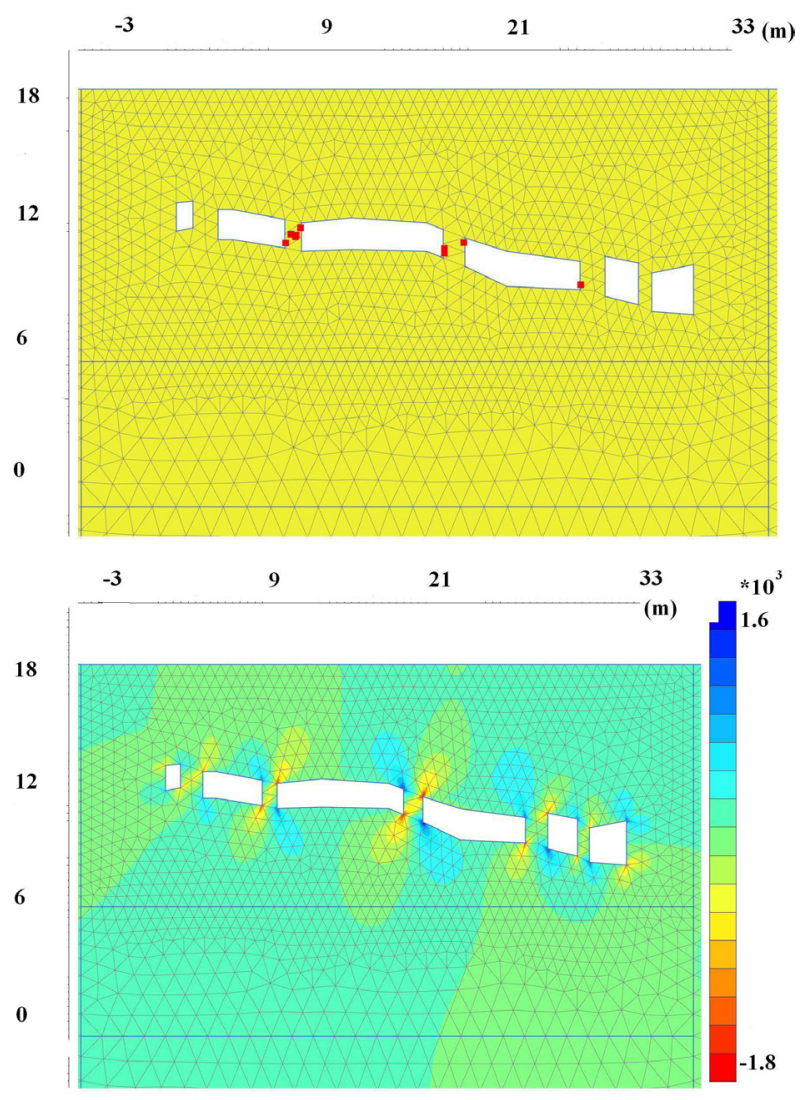

Figure 8. Analysis 1 (calcarenite with low degree of saturation; $G S I=95$ ): plastic points in the pillars of the underground quarry (above), and shear deformations in the underground quarry (below). Vertical scale is meters above sea level.

based on in-situ measurements. A numerical analysis implementing mechanical properties representative of low saturation degree conditions has been firstly carried out (Analysis 1); thereafter, an analysis implementing parameters representative of saturated conditions for the calcarenite, in the hypothesis of a rock mass characterized by low fractured conditions (GSI = 95; Analysis 2) has been performed. Such analysis is representative of conditions of calcarenite saturation at depth as an effect of long-term water infiltration from the ground surface, as typically observed during in situ surveys. Moreover, an analysis assuming saturated conditions of the calcarenite and strength parameters representative of a moderate degree of fracturing $(\mathrm{GSI}=80)$ has been also performed.

The latter hypothesis follows field surveys, when at least a discontinuity set, NW-SE directed, has been identified. Thus, for this analysis a shear strength envelope, with c' $=75 \mathrm{kPa}$ and $\varphi^{\prime}=35^{\circ}$ (Table 1; Analysis 3), has been used accordingly. 


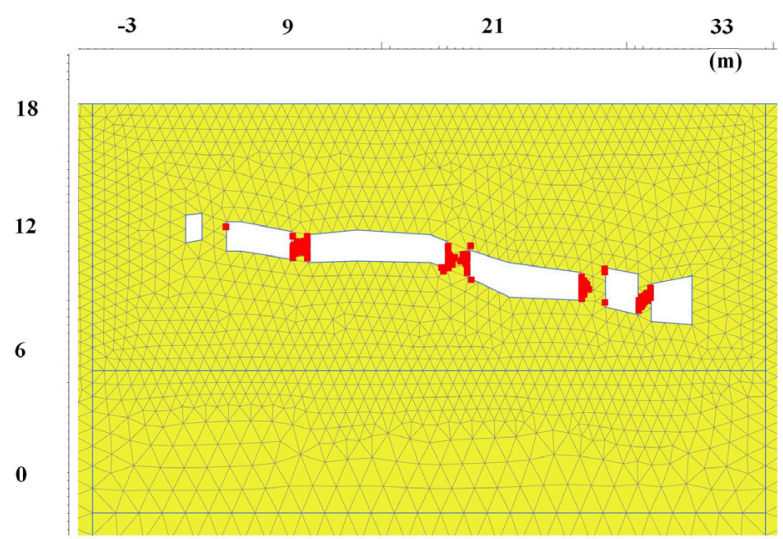

Figure 9. Analysis $2(S=1 ; G S I=95)$ : plastic points in the pillars of the underground quarry. Vertical scale is meters above sea level.

A value of the coefficient of at rest earth pressure equal to $\mathrm{K}_{0}=1$ has been assigned to prescribe the initial stress state of the model.

Afterwards, the excavation stages have been simulated in the model up to the current geometry of the cavity rooms.

When stable conditions resulted from the model, a " $c-\varphi$ reduction" analysis (Matsui \& San, 1992), reproducing a gradual reduction of the strength properties of the rock mass up to the global failure, has been performed in order to derive the safety factor.

For analysis 1 (dry calcarenite; GSI =95), the numerical results show stable conditions for the rock mass. However, the analysis also indicates clear plastic zones and the accumulation of shear strains (Figure 8) within the pillars delimiting the excavation rooms. Based on the strength reduction procedure, a safety factor of $F=1.7$ has been deduced in this case.

Analysis 2 (saturation degree $\mathrm{S}=1$; GSI $=95$ ) shows a well-advanced plastic state inside the pillars dividing the rooms, with inclined plastic zones that propagate from the upper and lower pillar corners between adjacent rooms (Figure 9). For this analysis, the "c- $\varphi$ reduction" calculation stage indicates a safety factor of $\mathrm{F}=1.3$ and the associated failure mechanism is shown in terms of contours of incremental shear strains and in terms of final deformed mesh (Figure 10). The upper part of Figure 10 suggests a failure process characterized by an inclined shear zone on the left-hand side of the quarry and an arch-shaped shear zone along the right-hand side. The lower part of Figure 10 shows the final profile of the ground surface as a consequence of the failure process associated to the sinkhole. Therefore, the results define a failure mechanism which is in good agreement with the reconstruction of the collapse process, based on the field surveys (see Figure 7).

Finally, analysis 3 (saturation degree $\mathrm{S}=1$; GSI $=80$ ) implies a lack of convergence of the numerical model and consequently unstable conditions of the rock mass ( $\mathrm{F} \leq 1$; Figure 11). This highlights the role of rock fracturing to enhance the failure process that led to the occurrence of sinkhole.

\section{A comparison with similar situations in southern Italy}

The situation described in the present paper for the underground quarry at Marsala is certainly not limited to this territory, or to Sicily. Presence of ancient

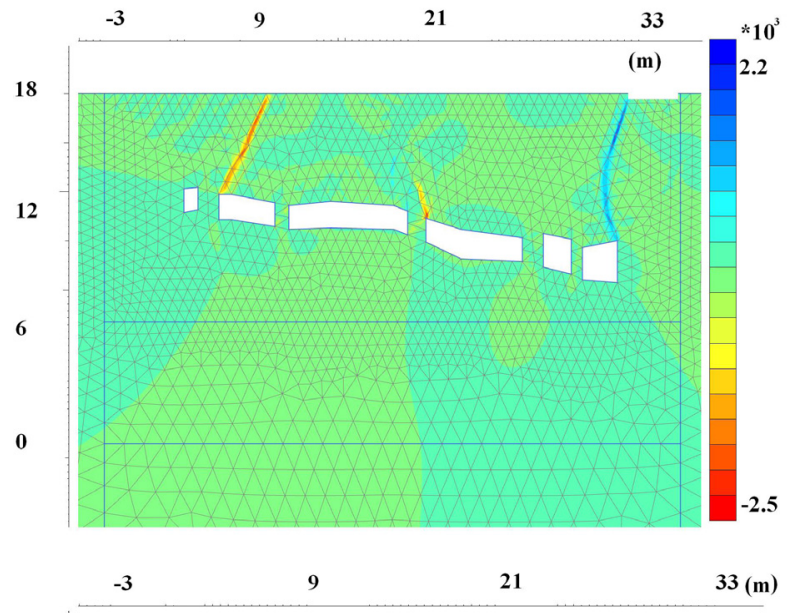

18

12

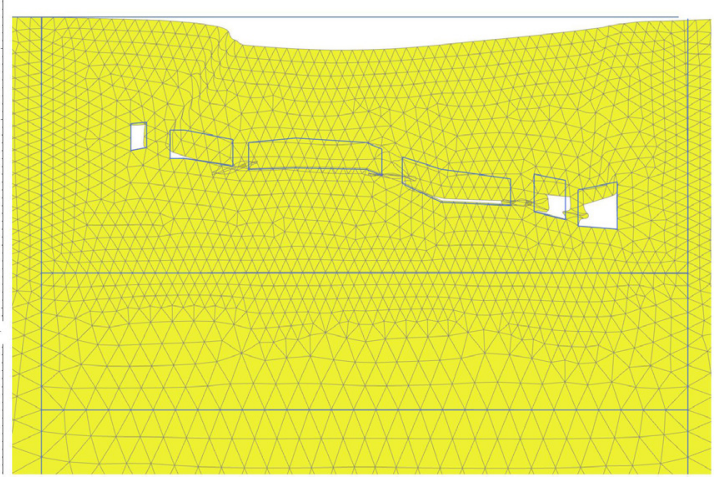

Figure 10. Analysis $2(S=1 ; G S I=95)$ : shear strains in the region overlying the underground quarry (above), and final profile of the ground surface as a consequence of the collapse (below). Vertical scale is meters above sea level. 


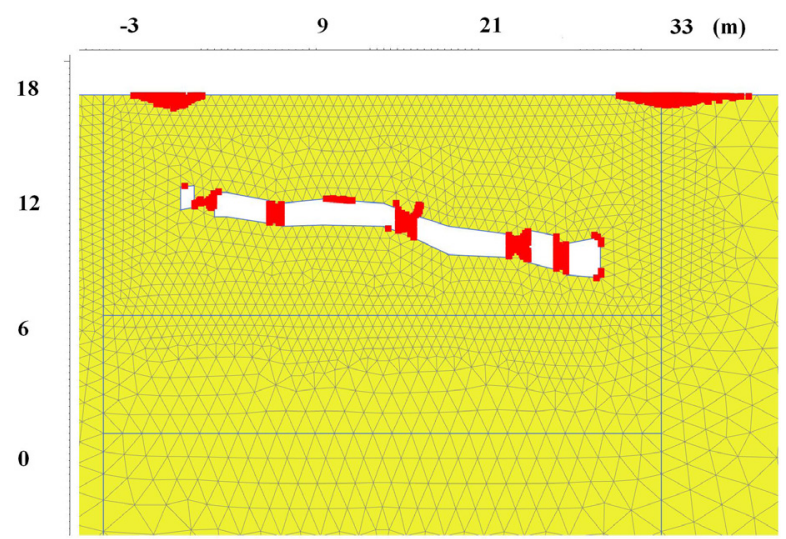

Figure 11. Analysis $3(S=1 ; G S I=80)$ : plastic points in the pillars of the underground quarry. Vertical scale is meters above sea level.

underground sites used for the extraction of building and ornamental materials is extremely common in Italy, especially in the southern regions, and in those areas (i.e. Tuscany, Latium, Campania) where local geology is characterized by volcanic rocks.

It is worth here to recall the many experiences carried out during the last decades in Apulia, probably one of the regions with the highest number, and typological variety as well, of man-made cavities in Italy.

Among many types of cavities, underground quarries have produced many subsidences and sinkholes (Parise, 2010, 2012).

This because these sites, that were originally located at the outskirts of towns, have been progressively included within the built-up areas, due to progressive expansion of the urbanization, so that in many cases the constructions realized in the last decades have been built above the quarries. The cases of Altamura, Gallipoli, Cutrofiano, Canosa di Puglia are the most documented (Parise, 2012; Pepe et al., this volume). A very high percentage of the historical parts of Apulian towns are built above a complex subterranean network of quarries. Looking at the chronology of sinkhole events so far reconstructed for Apulia (Parise \& Fiore, 2011), in the last decade, at least 13 sinkhole events $(34 \%$ of the total number of sinkholes with a temporal reference) can be attributed to underground quarries. There is therefore a very critical situation in terms of civil protection, as in Sicily; in this latter region, however, the problems are still greater, due to the fact that the rocks potentially interested by such subterranean activity are represented by both volcanic rocks and recent calcarenite deposits (as in the Marsala case study).

Vulnerability of the sites is greatly increased by loss of precise locations of underground quarries, and by unavailability of a survey depicting the real directions of development of the subterranean passages, their sizes, and the interaction with the overlying built-up areas. These issues should be addressed in order to understand the instability conditions underground, and to reduce the risk of sinkhole collapses in the future.

\section{Conclusions}

In situ surveys, and numerical analyses carried out with the finite element method (FEM), allowed the authors to hypothesize the formation conditions of anthropogenic sinkholes in Marsala (Italy).

Preliminary results indicate that the genesis of the sinkhole can be attributed to the saturation of the calcarenite, along with the presence of discontinuity systems. These conditions can decrease the strength needed for the stability of the rock mass above the underground quarry.

In the case study the use of 2D modeling creates resolution limits. To obtain a more realistic representation of the tenso-deformative behavior of the rock mass a 3D model is strongly needed. 3D modeling will be part of future investigations from our working group.

In addition, it is important to notice that even if the effective quarry area is $2000 \mathrm{~m}^{2}$, only $1500 \mathrm{~m}^{2}$ are actually carved, giving a "rock/void" ratio of 1 to 3 or 1 to 4 if we consider the non-excavated portions (i.e. pillars, walls) over the entire area. As a consequence, after the formation of the quarry, the weight of the rock portion above a chamber is distributed over a surface reduced of $1 / 4$ of the initial area. The stress on the pillars, which are often not thick enough, increases 4 times.

The case study here presented is one example of many situations that exist in Sicily, as well as in several other regions of Italy, due to the presence of underground quarries.

Caving exploration and surveys, structural analyses (including evaluation of instability features), topographic monitoring at the surface, and geotechnical 
modeling, represent some of the standard procedures used to evaluate the real possibility of propagation of the underground failures toward the surface.

Further, it allows researchers to obtain precious information to design rehabilitation works, or to help decision makers in the choice of the most proper action for the involved sites.

\section{Acknowledgments}

The authors would like to thank Francesco Patti of the Municipality of Marsala for the access to the study site. Guido Umilità and Rosalia Davì whose useful suggestions greatly improved the quality of the article. Many thanks to the reviewers Thomas L. Dobecki and Yongli Gao for their helpful comments and suggestions.

\section{References}

Arces M, Aversa S, Lo Cicero G, Nocilla N. 2000. The Pleistocene "Calcareniti di Marsala": geotechnical and sedimentological characterisation. Mem. Soc. Geol. It.,55: 483-489.

Di Maggio C, Agate M, Contino A, Basilone L, Catalano R. 2009. Unità a limiti inconformi utilizzate per la cartografia dei depositi quaternari nei Fogli Carg della Sicilia nord-occidentale. Il Quaternario 22 (2): 345-364.

Hoek E. 1994. Strength of rock and rock masses. ISRM News Journal, 2 (2): 4-16.

Lollino P, Martimucci V, Parise M. 2013. Geological survey and numerical modeling of the potential failure mechanisms of underground caves. Geosystem Engineering, in press.

Matsui T, San KC. 1992. Finite element slope stability analysis by shear strength reduction technique. Soils \& Foundation, 32 (1): 59-70.

Parise M. 2010. The impacts of quarrying in the Apulian karst. In: Carrasco F, La Moreaux JW, Duran Valsero JJ, Andreo B. editors. Advances in research in karst media. Springer: pp. 441-447.

Parise M. 2012. A present risk from past activities: sinkhole occurrence above underground quarries. Carbonates and Evaporites 27 (2): 109-118.

Parise M, Fiore A. 2011. Chronology of sinkhole events in Apulia, Italy. Geophysical Research Abstracts 13: 3225.

Parise M, Lollino P. 2011. A preliminary analysis of failure mechanisms in karst and man-made underground caves in Southern Italy. Geomorphology 134: 132-143.
Pepe P, Pentimone N, Garziano G, Martimucci V, Parise M. 2013. Lessons learned from occurrence of sinkholes related to man-made cavities in a town of southern Italy. These proceedings.

Ruggieri G, Unti M. 1974. Pliocene e Pleistocene nell'entroterra di Marsala. Boll. Soc. Geol. It.93: 723-733.

Ruggieri G, Unti A, Unti M, Moroni MA. 1975. La calcarenite di Marsala (Pleistocene inferiore) e i terreni contermini. Boll. Soc. Geol. It. 94: 1623-1657.

Salvini F. 2011. Daisy 3, the structural data integrated analyzer. Free distribution by e-mailing to daisy@, uniroma3.it. Dipartimento di Scienze Geologiche, Università di "Roma Tre", Roma.

Waltham T. 2002. The engineering classification of karst with respect to the role and influence of caves. International Journal of Speleology 31 (1/4): 19-35.

Waltham T, Bell F, Culshaw M. 2005. Sinkholes and Subsidence: Karst and Cavernous Rocks in Engineering and Construction. Berlin: Springer. 
272 NCKRI SYMPOSIUM 2 13TH SINKHOLE CONFERENCE 